\title{
Potential Environmental and Ecological Effects of Global Climate Change on Venomous Terrestrial Species in the Wilderness
}

\author{
Robert K. Needleman, MD; Isabelle P. Neylan; Timothy Erickson, MD, FACEP, FACMT, FAACT \\ From the Department of Emergency Medicine, Cook County Hospital, Chicago, IL (Dr Needleman); the Institute of Marine Sciences, University of \\ North Carolina Chapel Hill, Morehead City, NC (Ms Neylan); and the Department of Emergency Medicine, Division of Medical Toxicology, \\ Brigham and Women's Hospital, Harvard Medical School, Harvard Humanitarian Initiative, Boston, MA (Dr Erickson).
}

Introduction-Climate change has been scientifically documented, and its effects on wildlife have been prognosticated. We sought to predict the overall impact of climate change on venomous terrestrial species. We hypothesize that given the close relationship between terrestrial venomous species and climate, a changing global environment may result in increased species migration, geographical redistribution, and longer seasons for envenomation, which would have repercussions on human health.

Methods-A retrospective analysis of environmental, ecological, and medical literature was performed with a focus on climate change, toxinology, and future modeling specific to venomous terrestrial creatures. Species included venomous reptiles, snakes, arthropods, spiders, and Hymenoptera (ants and bees). Animals that are vectors of hemorrhagic infectious disease (eg, mosquitos, ticks) were excluded.

Results-Our review of the literature indicates that changes to climatic norms will have a potentially dramatic effect on terrestrial venomous creatures. Empirical evidence demonstrates that geographic distributions of many species have already shifted due to changing climatic conditions. Given that most terrestrial venomous species are ectotherms closely tied to ambient temperature, and that climate change is shifting temperature zones away from the equator, further significant distribution and population changes should be anticipated. For those species able to migrate to match the changing temperatures, new geographical locations may open. For those species with limited distribution capabilities, the rate of climate change may accelerate faster than species can adapt, causing population declines. Specifically, poisonous snakes and spiders will likely maintain their population numbers but will shift their geographic distribution to traditionally temperate zones more often inhabited by humans. Fire ants and Africanized honey bees are expected to have an expanded range distribution due to predicted warming trends. Human encounters with these types of creatures are likely to increase, resulting in potential human morbidity and mortality.

Conclusions-Temperature extremes and changes to climatic norms may have a dramatic effect on venomous terrestrial species. As climate change affects the distribution, populations, and life histories of these organisms, the chance of encounters could be altered, thus affecting human health and the survivability of these creatures.

Keywords: snakes, spiders, Hymenoptera, bees, ants

\section{Introduction}

Climate change has been scientifically documented, ${ }^{1}$ and its effects on wildlife have been prognosticated. Bites and

Corresponding author: Dr. Robert K. Needleman, Cook County Hospital, Department of Emergency Medicine, Chicago, IL 60612; e-mail: rneedleman@cookcountyhhs.org.

Submitted for publication May 2017.

Accepted for publication November 2017. stings from terrestrial venomous species represent a global public health issue. Venomous snakes alone account for 2.5 million bites per year, with more than 85,000 annual deaths. ${ }^{2,3}$ Ants sting 9.3 million people each year. Other Hymenoptera species such as bees account for more than 1 million stings annually. Anaphylaxis secondary to Hymenoptera envenomation affects roughly $3 \%$ of the general population. ${ }^{4}$ Systemic reactions leading to life-threatening manifestations occur in approximately 
$0.4-0.8 \%$ of envenomated children and $3 \%$ of envenomated adults. ${ }^{5}$

Most terrestrial venomous species are ectoderms and are therefore closely tied to ambient temperature. Wide scientific consensus on the presence of anthropogenic climate change has been established, and its effects on wildlife have been prognosticated in environmental and ecology communities. ${ }^{1}$ However, to our knowledge, no study has looked at the global effects of climate change on terrestrial venomous creatures. This review will uniquely focus on climate change and toxinology specific to snakes, spiders, and Hymenoptera species (bees and ants). As more people venture into the wilderness and as climate change affects the distribution, populations, and life histories of many organisms, the chance of encounter could be altered, affecting human health and the survivability of these venomous creatures. Already many forms of media have dramatized the effects climate change may have on human interaction with venomous species. ${ }^{6,7}$ With possible shifts in venomous species' regions, limited supply of antivenom may require redistribution to newly populated areas. Additionally, medical practitioners in these new regions may need further education for the timely diagnosis and rapid treatment of envenomation.

Empirical evidence has been accumulating that geographic distributions of many species have already shifted due to changing climatic conditions, particularly away from the equator in polar directions. We sought to review the overall impact of climate change on venomous terrestrial species. We hypothesize that given the close relationship between terrestrial venomous species and climate, a changing global environment may result in terrestrial venomous species migration, geographical redistribution, and longer seasons for envenomation, which may also have repercussions on human health. To this end, we evaluated existing published research that describe and analyze both present and future effects of anthropogenic climate change on individual venomous terrestrial species.

\section{Methods}

We conducted a retrospective analysis of environmental, ecological, and medical literature with a focus on climate change, toxinology, and future modeling specific to venomous terrestrial creatures. Species included venomous reptiles, snakes, arthropods, spiders, and Hymenoptera. Animals that are vectors of hemorrhagic infectious disease (eg, mosquitos, ticks) were excluded.

We performed an article review search using the Web of Science core database collection, which provides access to several databases including the Science
Citation Index Expanded database (1900-present day), Conference Proceedings Citation Index database (1990-present day), and Book Citation Index database (2005-present day). Additionally, the PubMed NCBI database was used in our search. The keywords used in our search included the following: climate change, anthropogenic climate change, climate, global warming, temperature change, environmental change, envenomation, venomous, distribution, snakes, elapid, viper, rattlesnake, snake bite, ants, fire ants, spiders, recluse, reclusa, black widow, arachnid, scorpions, Africanized honey bees, killer bees, and bees. Each keyword was used independently and, when appropriate, in combination with additional keyword(s) to identify relevant articles. The keyword search generated 705 citations, of which 132 were reviewed. From the reviewed material, 64 journal articles, 7 text book references, and 7 governmental/organizational reports were deemed relevant and included in the results section.

We further analyzed multiple ecological niche model studies that project future species distribution. Ecological niche modeling is an area of study in which species distribution algorithms are created by combining present day species geographic occurrences with climate and environmental predictor variables. These algorithms can then be combined with future climate change scenario information, creating future distribution projections. ${ }^{8}$

\section{Results}

\section{SNAKES}

Venomous snakes exist on every continent (except Antarctica) and in almost every country. Approximately 2.5 million venomous snakebites to humans occur per year and result in 85,000 deaths worldwide, mostly in tropical and subtropical regions of Africa, Asia, and America. $^{9-11}$ In the United States specifically, $20 \%$ of the 120 indigenous snake species are considered venomous (Figure 1). ${ }^{12,13}$

Snakes, like other reptiles, are ectothermic animals that rely on external heat sources to contribute to many physiological processes. For snakes, increased temperatures have been noted to increase activity time, metabolic rate, digestive function, and activity levels and to extend aboveground time periods. ${ }^{14}$ Given the strong correlation between temperature and snake activity, research has evaluated whether a changing climate will lead to changes in distribution. One retrospective study conducted in China noted 9 snake species had significant distribution changes over the last 50 years, largely due to changes of the country's thermal index. ${ }^{15}$

Other researcher groups projected future distribution of venomous snakes using climate change forecasts. Nori 


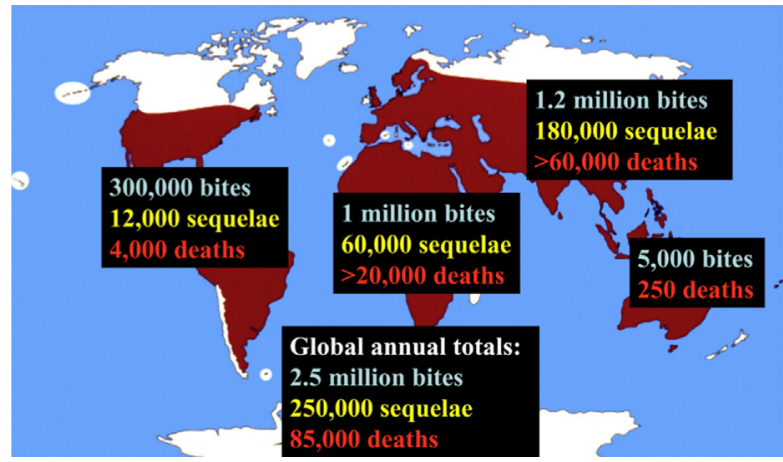

Figure 1. The global burden of snakebites. Source: Gutierrez et al. ${ }^{13}$ Used with permission.

et al forecasted the suitable climate spaces for the 5 most venomous snake species in Argentina in 2030 and 2080. They discovered net expansion of suitable climate spaces for 4 snake species with moderate "north to south" displacement. This geographic expansion includes more populated provinces in central-eastern Argentina, where few venomous snakebites currently occur (Figure 2). ${ }^{16}$
Another study projected the current and future (2050) snakebite risk of 90 venomous snake taxa across the Americas given anticipated climate change, including Agkistrodon contortrix (copperhead). Overall, the study anticipated that total risk area size would increase northward into northern United States and Canada and southward in Argentina and Chile resulting in an additional 5.5 to 6.7 million people potentially exposed to snakebites. In contrast, future projections in Latin America were mixed based upon species type; approximately half the species showed decreased distributional potential. Interestingly, suitable climatic conditions are expected to expand into Chile, where no venomous snakes currently exist. Another investigation examined the 2100 distribution of 11 North American rattlesnake species (Crotalus). Taking into account rattlesnake adaptability rate, including migration speed, they predict a northern migration of species; however, they also noted significant decreases in distribution with liberal climate projections $\left(6.4^{\circ} \mathrm{C}\right)$ because the snakes would not be able to adapt quickly

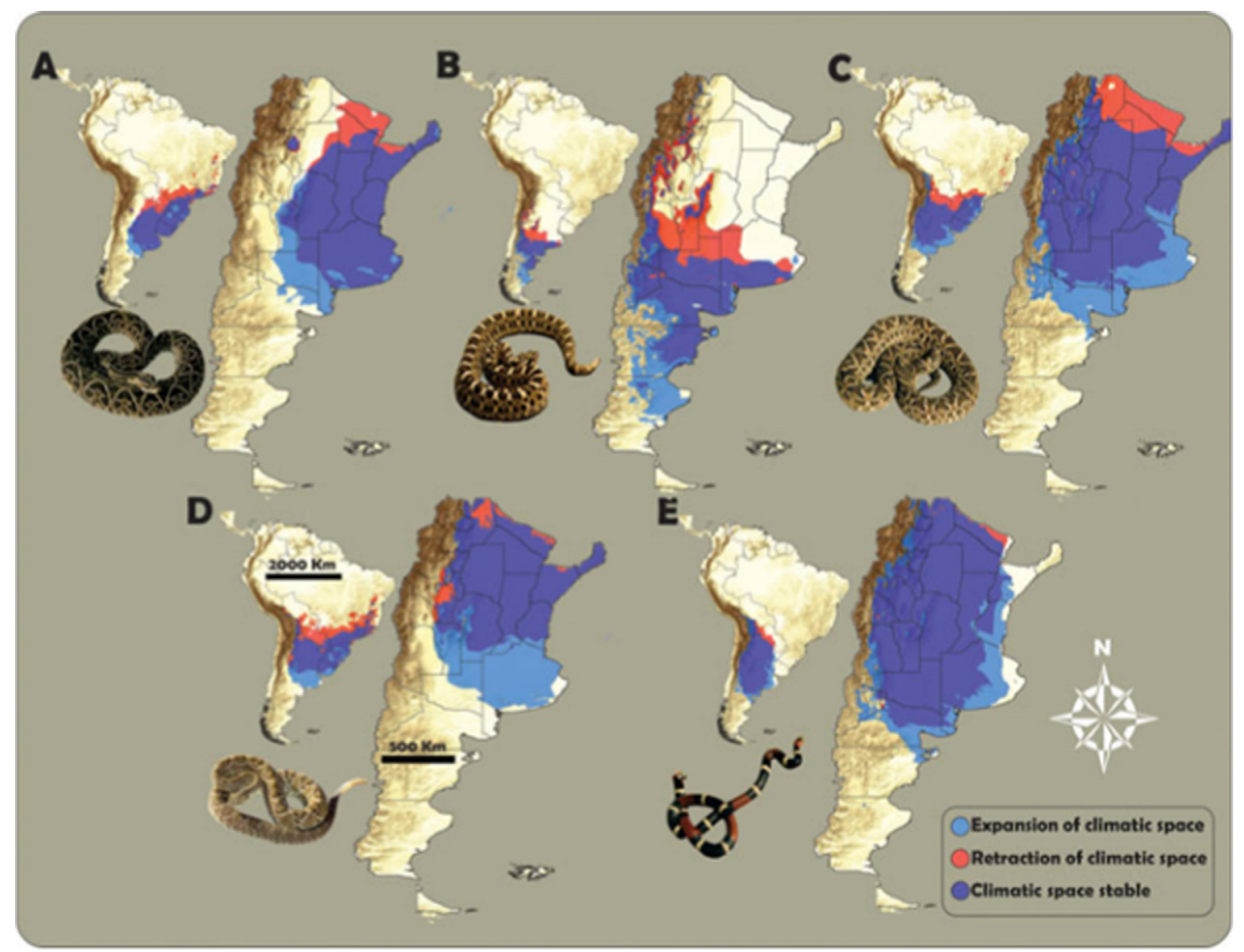

Figure 2. Changes in suitable climate spaces between present climatic conditions and 2080 for 5 snake species. A, Bothrops alternatus. B, Bothrops ammodytoides. C, Bothrops diporus. D, Crotalus durissus terrificus. E, Micrurus pyrrhocryptus. Source: Nori et al. ${ }^{16}$ Used with permission. 

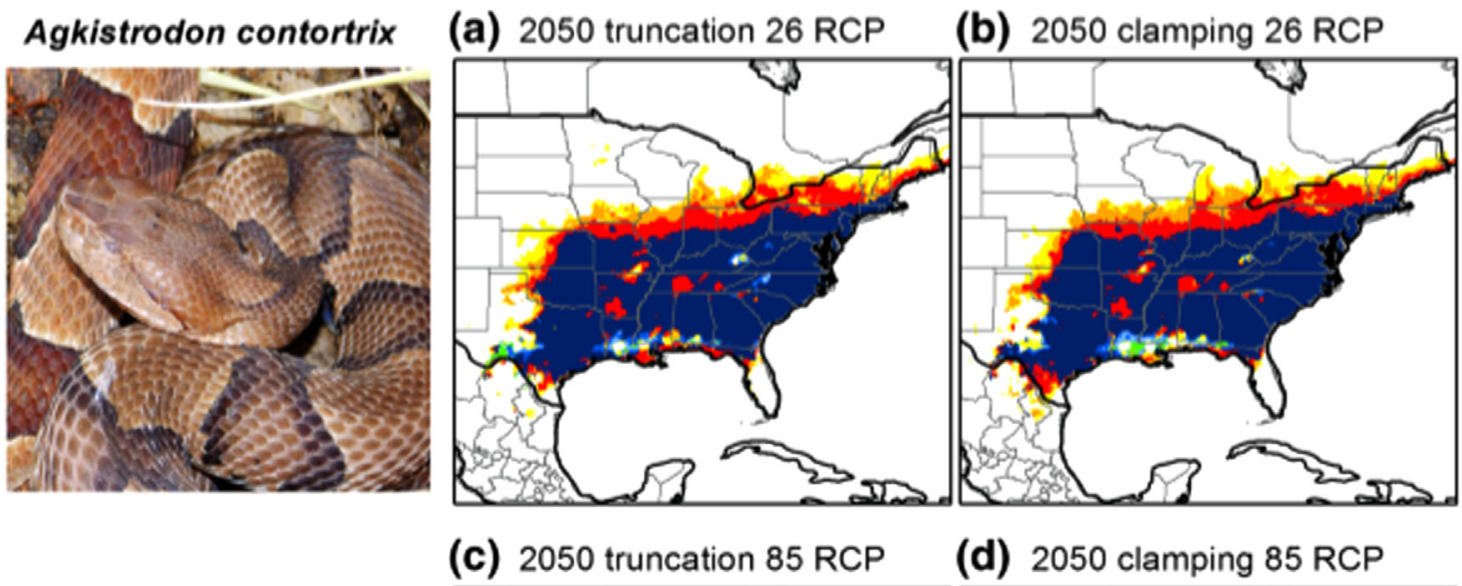

(d) 2050 clamping $85 \mathrm{RCP}$
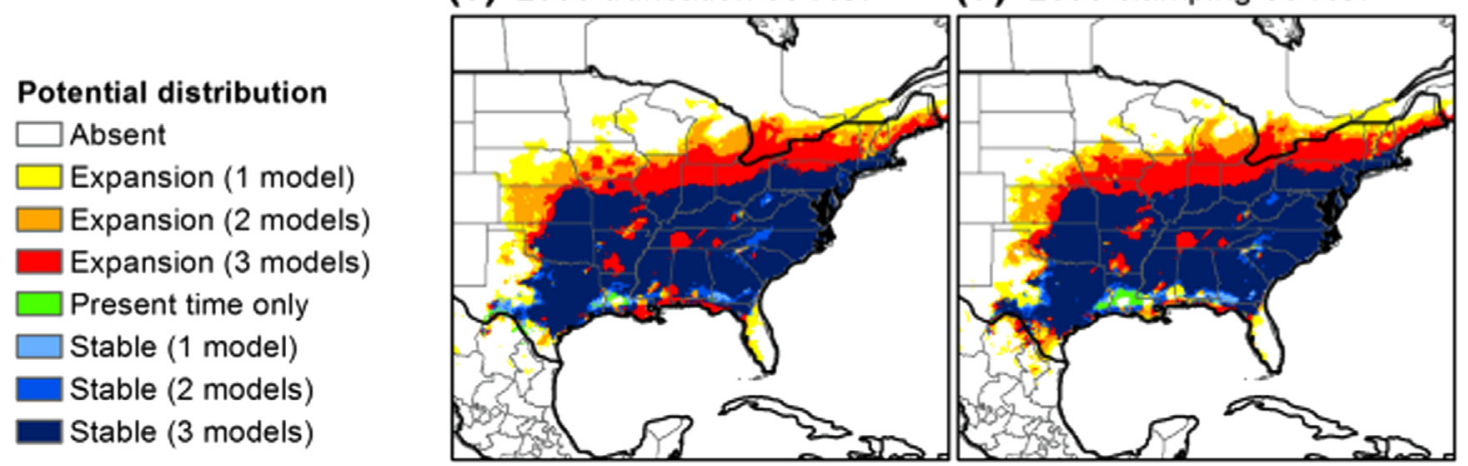

Figure 3. Changes in suitable climatic spaces and potential distributions between current and future conditions for Agkistrodon contortrix (copperhead viper). The 4 maps are categorized by different representative concentration pathways (RCPs), which are greenhouse gas concentration trajectories adopted by the Intergovernmental Panel on Climate Change. Two representative pathways (RCP 26 and RCP 85) were used in the modelling, which represent relatively conservative and liberal degrees of climate change expected, respectively. Source: Yanez-Arenas et al. ${ }^{17}$ Used with permission.

enough to their rapidly changing climate (Figures 3, 4, and 5). ${ }^{17-18}$

\section{SPIDERS}

There are nearly 40,000 species of spiders worldwide, ${ }^{19}$ most of which cannot inflict serious bites on humans. ${ }^{20}$ However, there are a few medically relevant spiders in North America that produce toxic venoms (eg, black widow, brown recluse, and hobo spiders), which can lead to local reactions, systemic illnesses, neurotoxicity, and hematotoxicity. ${ }^{21}$ Spiders, like other ectotherms, are closely dependent on temperature to drive physiological and behavioral traits, but to date few studies have investigated the historical change of spider distribution with the increase in temperature over the past century. ${ }^{22}$ Despite the limited historical evidence, there is likely a close relationship between temperature and spider survival.

Brown recluse spiders (Loxosceles reclusa) are one of the most well-known venomous spiders indigenous to the United States. Their bites often cause necrotic skin lesions and rarely systemic complications including nausea, vomiting, fever, chills, arthralgias, thrombocytopenia, rhabdomyolysis, hemoglobinuria, renal failure, and hemolysis. ${ }^{21,23-25}$ Currently, L reclusa is found in the south-central United States, from southern Illinois to Texas and from eastern Tennessee to Kansas, with cold temperature contributing heavily to distribution boundaries. $^{26}$ Research evaluating climate change dispersal projections found a significant northward shift. However, the overall amount of suitable area did not differ by more than $7 \%$ between present and future projections, as northward migration was matched by distribution loss in the southern-most regions (Figures 6 and 7. $)^{8,27}$

Additional studies have modeled the future distribution of other spider species based upon projected temperature changes. One projection saw the European distribution of 10 spider species in 2050 using distribution models based on climate change and human land usage. The results of this study noted that projected distribution varied widely, with approximately half of species anticipated to experience negative net change 
(a) Present time

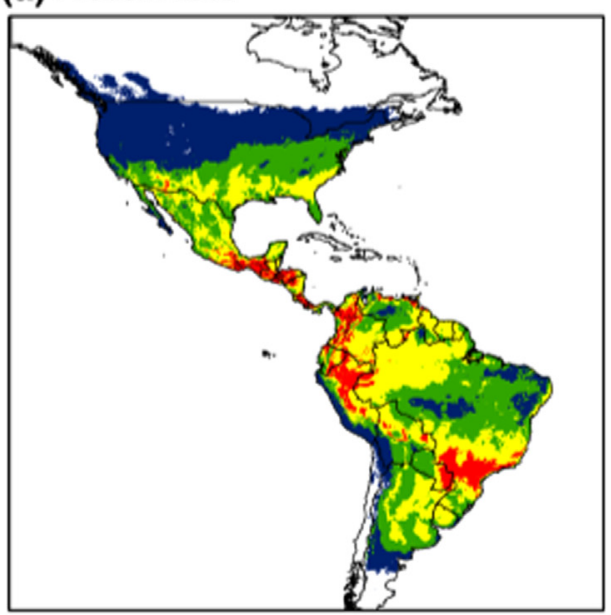

(c)

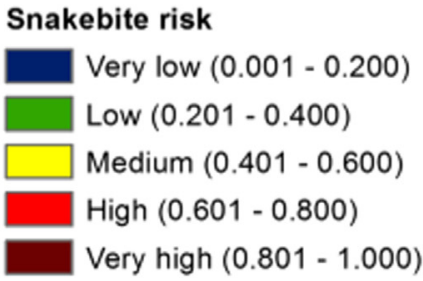

Standard deviation

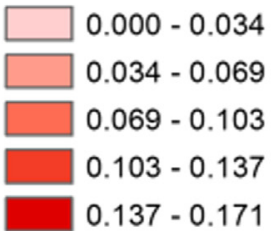

(b) 2050 consensus

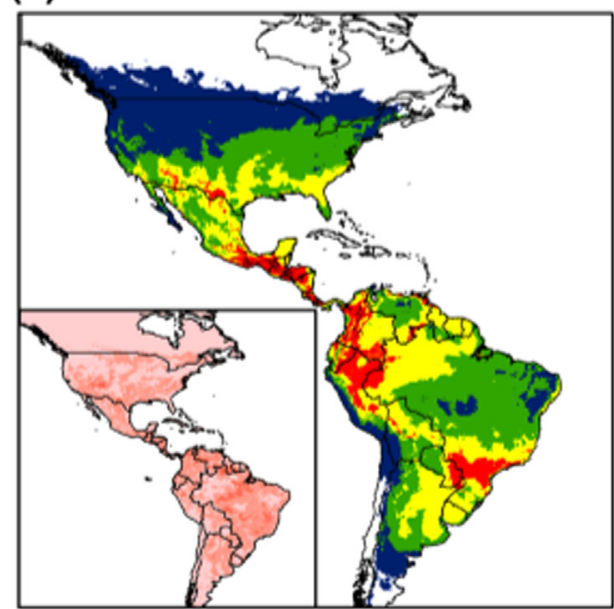

2050 clamping RCP 26

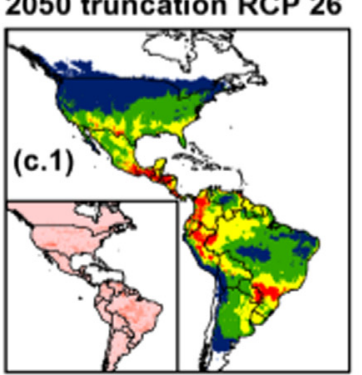

2050 truncation RCP 85
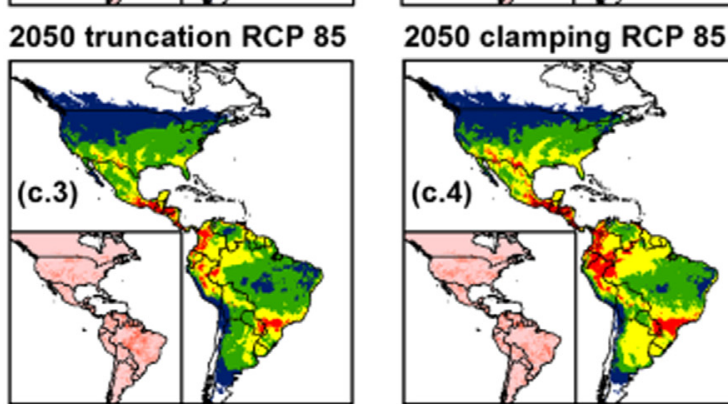

2050 clamping RCP 85

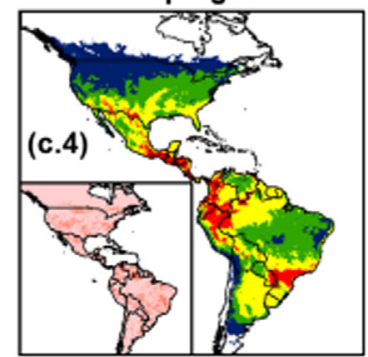

Figure 4. Current and future snakebite risk predictions in America and associated uncertainty (standard deviation). Source: Yanez-Arenas et al. ${ }^{17}$ Used with permission.

while the other half experienced positive net change. Despite such variability, all distribution patterns tended to shift north of their current range secondary to anticipated temperature increases at the northern distribution boundaries. $^{28}$

\section{ANTS}

The ant family (Formicidae) comprises 14,550 species ${ }^{29}$ with over 200 species established beyond their native range. ${ }^{30}$ The effects of such invasions are diverse and significant, including human medical impacts. In the United States alone, an estimated 17,000 people seek medical care from ant stings annually. ${ }^{31}$
Ants are poikilotherms and cannot regulate body temperature except by behavioral means such as basking and burrowing. Ants are therefore sensitive to environmental factors such as temperature and humidity, ${ }^{32,33}$ which directly influence performance, fitness maximization, invasion rate, and survival. ${ }^{34,35}$ As a result, ant distribution is largely limited by climate, ${ }^{36}$ which is thought to be the most important factor determining ant distributions on a global scale. ${ }^{37-39}$ Given this close relationship, the general consensus is that progression of climate change will alter distribution patterns.

One study selected 15 of the most invasive ant species and modeled suitable global areas in 2080 given climate 


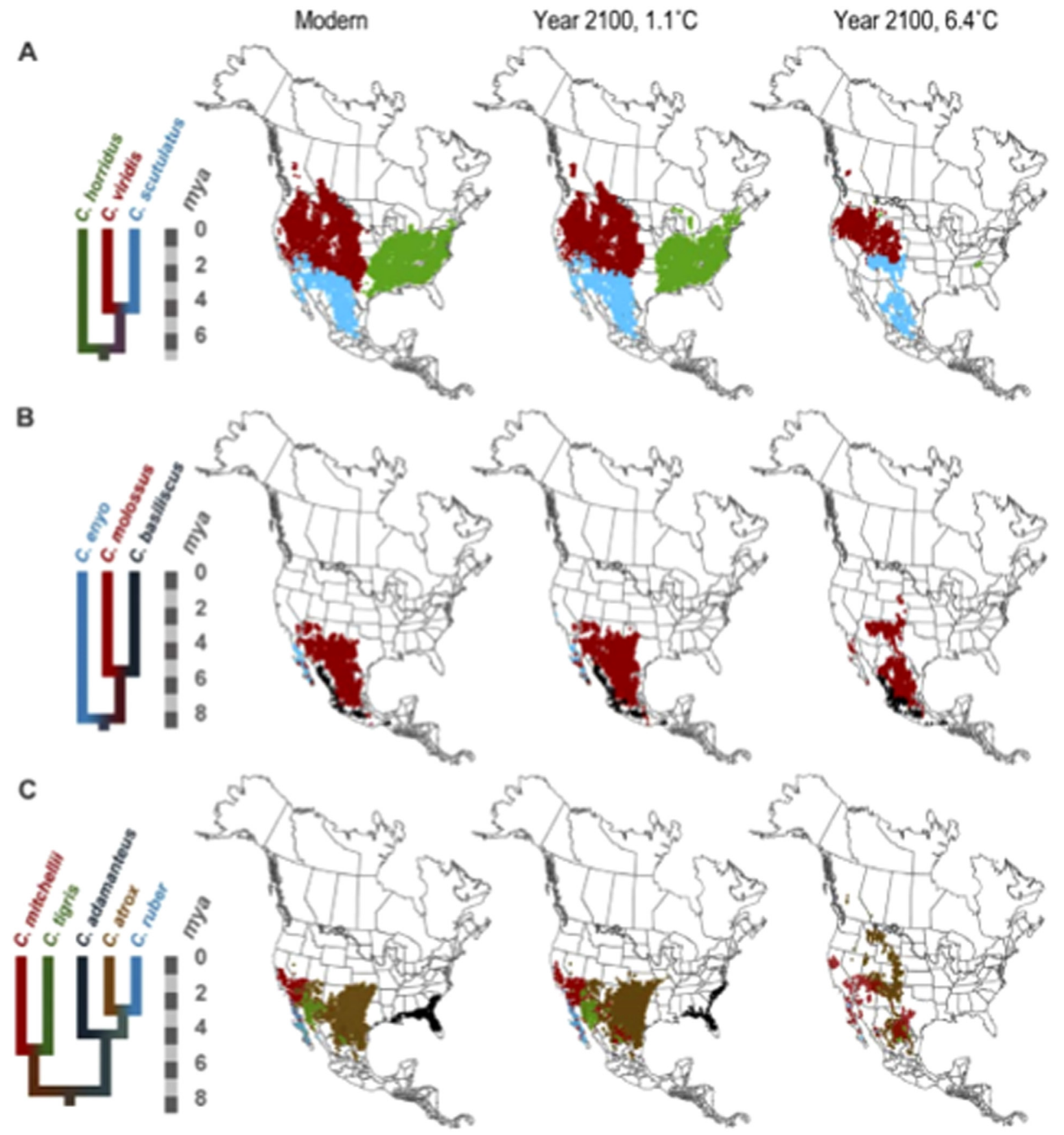

Figure 5. Current and future predictions of suitable habitats under 2 future climate scenarios for the year 2100 for 11 rattlesnake species. Source: Lawing et al. ${ }^{18}$ Used with permission.

change projections. ${ }^{40}$ In 2080,8 of the 15 species are predicted to have decreases in suitable areas, ranging from $-64 \%$ to $-3 \%$, while 5 of the 15 species experience increases. Notably, Solenopsis invicta (a stinging red imported fire ant) was projected to increase distribution in all geographical regions, with overall projections of $+16 \%$ in suitable area increase (Figures 8 and 9). ${ }^{40-42}$
In the United States, there are 5 known species of fire ants (Solenopsis), ${ }^{21}$ with S invicta responsible for $95 \%$ of North American clinical cases. ${ }^{43}$ Multiple stings in sensitive individuals can promote histamine release and lead to a spectrum of symptoms ranging from nausea, vomiting, and dizziness to angioedema and respiratory arrest, with $10 \%$ of victims having some degree of hypersensitivity reaction. ${ }^{44}$ 


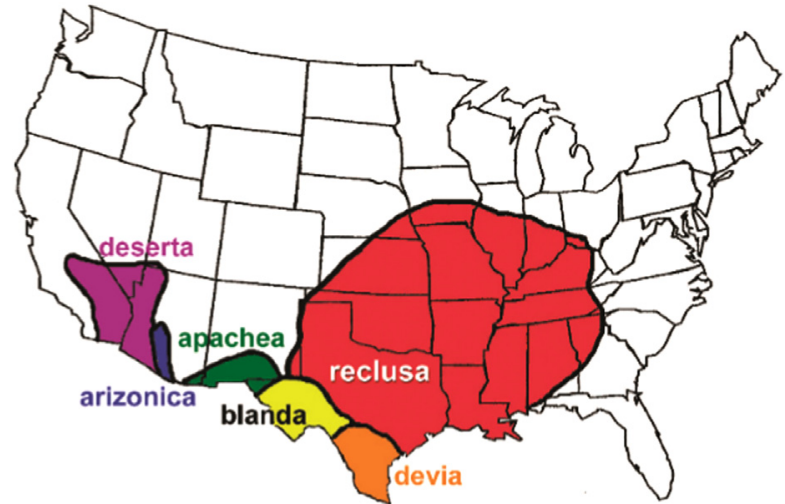

Figure 6. Map of distribution of the 6 Loxosceles species in North America. Source: Vetter. ${ }^{27}$ Used with permission.

$S$ invicta was accidentally introduced in the southern United States in the $1930 \mathrm{~s}^{45,46}$ and has since spread to 13 states, ${ }^{47}$ occupying much of the southern United States and California. ${ }^{48,49}$ Multiple studies have investigated the relationship between $S$ invicta and temperature and

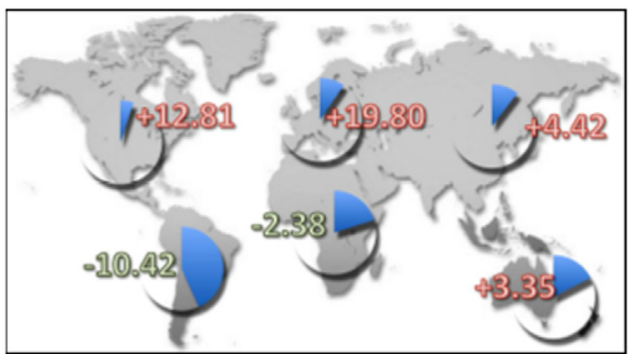

Figure 8. Average predicted proportion of current climatically suitable landmass on each continent for 15 invasive ants studied (blue pie chart) and predicted change after climate change (red percentage indicates an increase in range; green percentage indicates a decrease). Source: Bertelsmeier et al. ${ }^{42}$ Used with permission.

have found that high summer temperatures reduce population growth rates while winter temperatures stop colony growth and may cause colony death. ${ }^{50-53}$ Future projections in the United States anticipate further $S$ invicta distribution, in part due to temperature increases. One research team predicted that the US habitable area

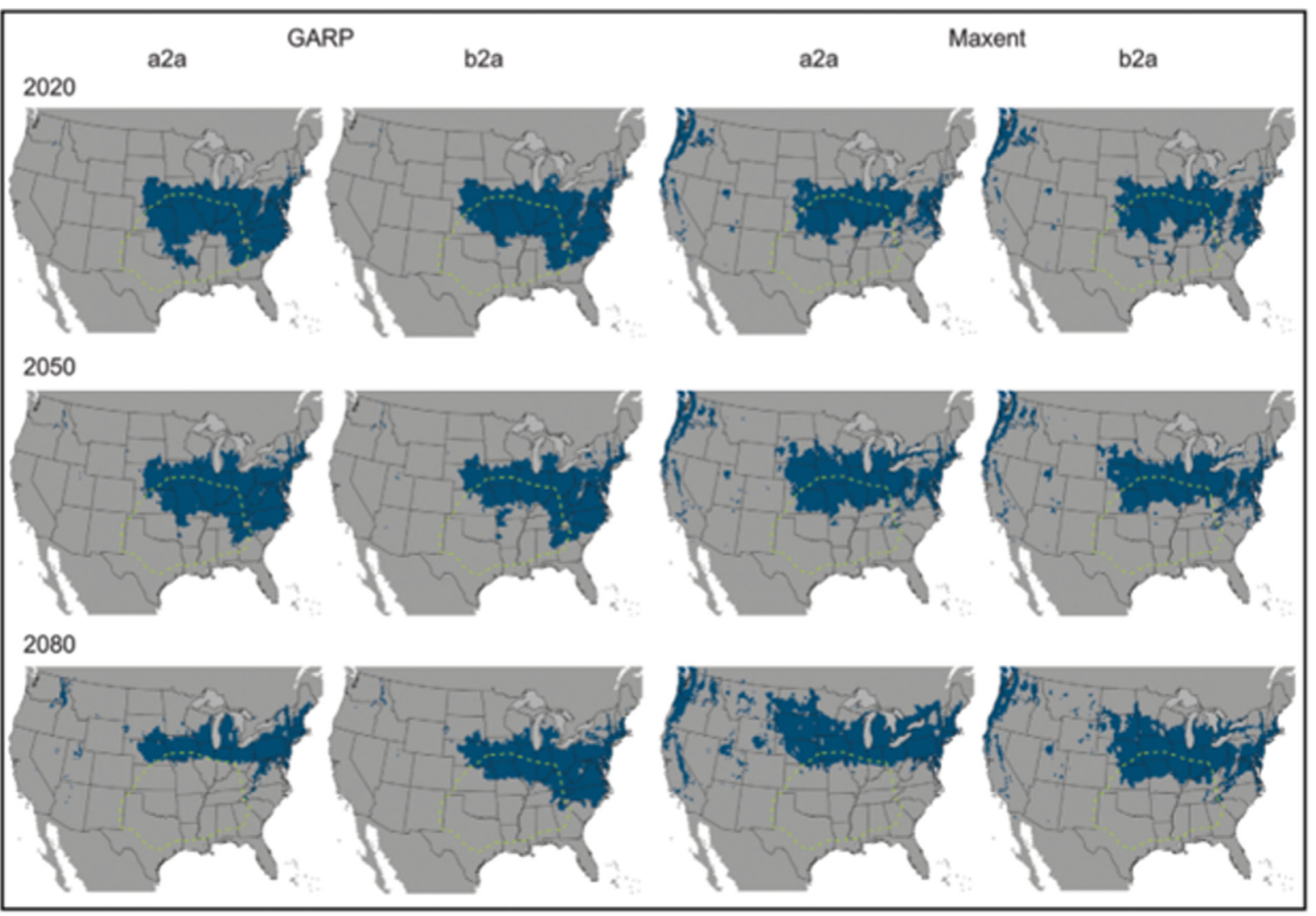

Figure 7. Future niche modeling results for 3 time slices: 2020, 2050, and 2080. This figure includes 2 methods of species niche model programs, Genetic Algorithm for Rule-set Prediction and Maxent. Both are machine-learning methods that rely upon combining species characteristics and survival probability to project distribution. Two climate scenarios were used: a2a (liberal) and b2a (conservative). The dotted shape indicated current distribution of $L$ reclusa. Source: Saupe et al. ${ }^{8}$ Used with permission. 


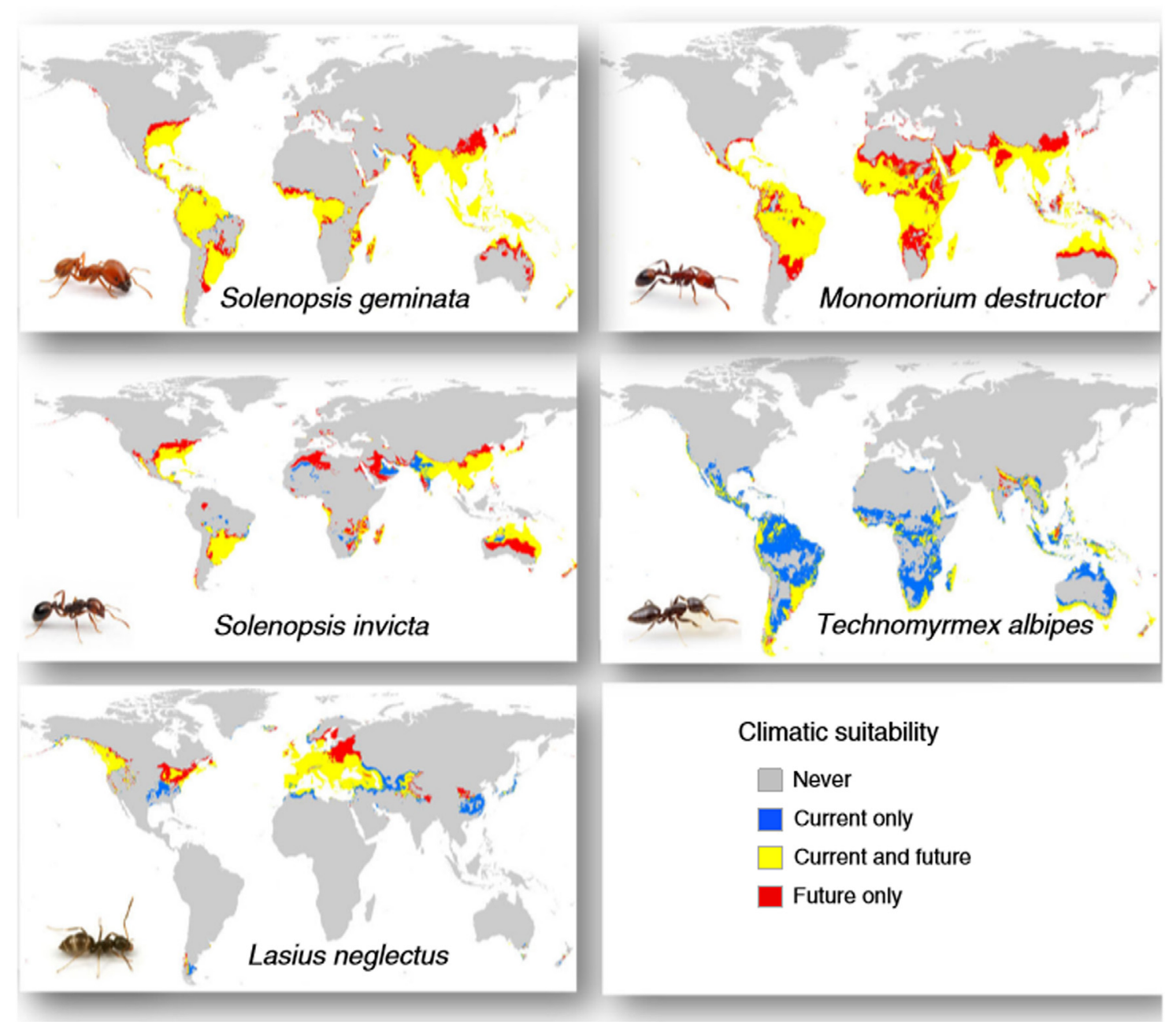

Figure 9. Spatial shift of suitable areas of 5 ant species that demonstrate different patterns. Source: Bertelsmeier et al. ${ }^{40}$ Used with permission.

may increase by approximately $5 \%$ over the next 40 to 50 years with northward expansion. By 2100, the habitable area is expected to increase to $>21 \%$ because global warming is expected to accelerate in the latter half of the upcoming century. ${ }^{54}$ Similar population expansion is expected in Australia, ${ }^{55}$ but unlike the United States, Australia does not have cold temperature extremes; $S$ invicta population growth therefore is expected to be more rapid (Figure 10). ${ }^{54,56}$

\section{AFRICANIZED HONEY BEES}

The south African honey bee subspecies Apis mellifera scutellata was introduced to Brazil in the mid-1950s ${ }^{57}$; it quickly escaped containment and began to hybridize with European honey bee strains, ${ }^{58-60}$ creating a hybrid species known as the Africanized honey bee. This new strain is notable for its highly aggressive behavior that has led to instances of massive bee envenomations to humans, which can result in rhabdomyolysis, ${ }^{61}$ acute renal failure, ${ }^{62}$ and even death. ${ }^{63}$ The Africanized honey bee spread rapidly through the neotropics, ${ }^{64-67}$ reaching the United States in $1990^{68,69}$ and spreading throughout the Southwest. ${ }^{70,71}$ Upon reaching the southern US border, the rate of spread slowed considerably. ${ }^{72}$

Multiple factors have contributed to the slowed and erratic progression through North America, including genetic, physiological, and climate variables. ${ }^{73-76}$ Winter temperatures seem to be a significant factor affecting range limitations, with no consensus on specific temperature limitations. ${ }^{61,77}$ One study evaluated the Africanized honey bee distribution patterns in southern Utah and

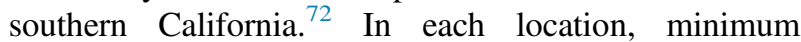
temperature was the primary controlling factor, with winter precipitation also contributing to distribution patterns. In general, Africanized honey bees in the United States appear to prefer habitats with moderate to low levels of winter precipitation and temperatures 


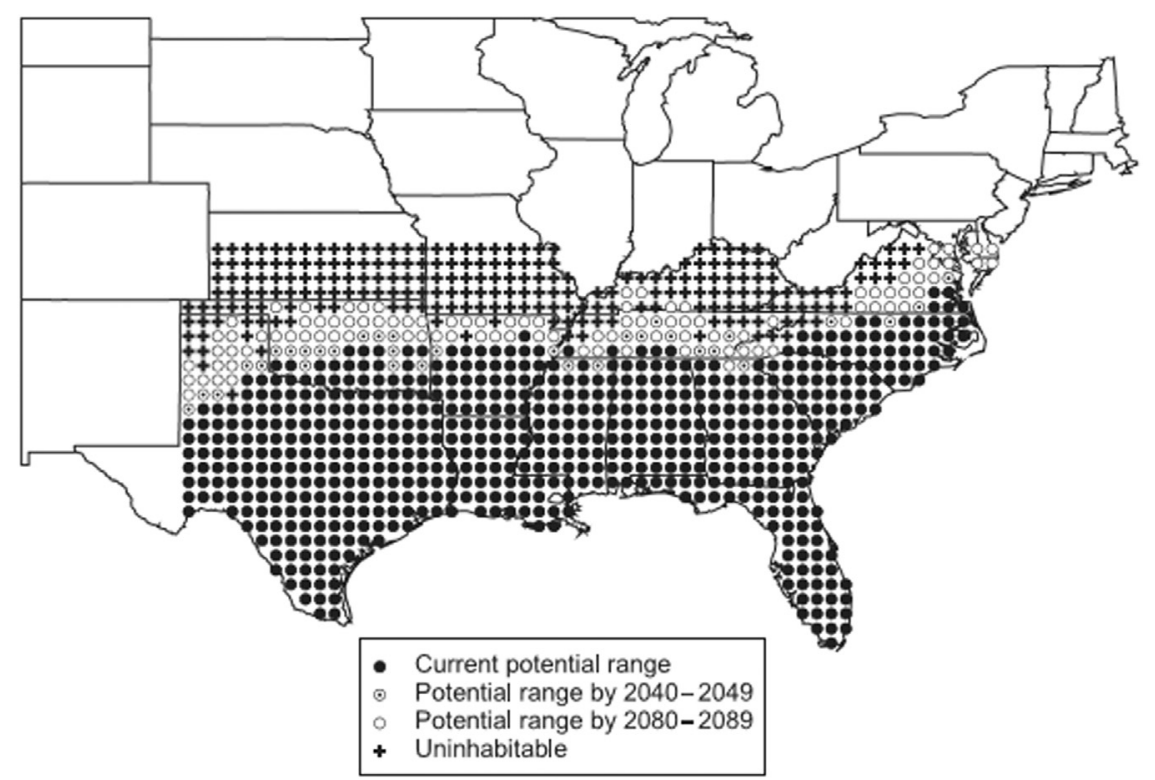

Figure 10. Map showing current and predicted potential range of Solenopsis invicta in the southeastern United States under expected climate change scenario. Source: Morrison et al. ${ }^{54}$ Used with permission.

that fluctuate greatly across seasons but rarely persist below freezing. ${ }^{72,73,76}$ As a result, with climate change and warming trends, Africanized honey bees could potentially extend their distribution hundreds of kilometers north. ${ }^{60}$

\section{Discussion}

Empirical evidence has already demonstrated that geographic distributions of many species have shifted due to changing climatic conditions. ${ }^{78-80}$ In the northern hemisphere, a northward shift has been observed in many other species, including birds, mammals, butterflies, mosquitos, and ticks, along with a southward shift in the southern hemisphere. ${ }^{81}$ Research has also found a strong relationship between climate conditions and terrestrial venomous species' geographic distribution. This literature review found that changes to climatic norms could have a dramatic effect on future terrestrial venomous creature distribution and, as a result, their impacts on health, with possible nonindigenous invasions of many medically relevant species.

The distribution specifics and the medical relevance of future population changes depend on the individual species. For snakes, ecological niche modeling projects a shift in suitable geography for many western hemisphere venomous species, moving northward in the northern hemisphere and southward in the southern hemisphere, increasing exposed populations by 5.5 million to 6.7 million people. Additionally, the Nori et $\mathrm{al}^{16}$ study predicted an increased incidence of Crotalus durissus terrificus and Bothrops diporus envenomation within the human population of Argentina because suitable climate spaces would reach densely populated areas. Expansion of venomous snakes into new geographic regions and densely populated areas would not only increase incidence rates but may require a redistribution of antivenom as well as training for medical professionals expected to treat such envenomations.

Spider projections also demonstrate a poleward migration of ideal temperature zones due to climate change. For $L$ reclusa, modeling projects a significant northward shift in the northern hemisphere, with northward geographic shift matched by distribution loss in the southern-most regions. Assuming relatively equal human populations densities in this region, overall incidence of $L$ reclusa bites may remain stable; however, the location in which they occur may change. For ants, the most significant effect may be the potential distribution increase of $S$ invicta within the United States, as projections anticipate a $21 \%$ increase in distribution of this medically relevant species.

However, suitable geographic changes do not necessarily result in actual species distributional change because the species must migrate to remain within ideal temperature zones. For those able to migrate to match the changing temperatures, new geographical locations will potentially open. For those species with limited distribution capabilities, the rate of climate change may accelerate faster than species can adapt and migrate, causing population disruption or decline. ${ }^{82}$ As a result of climate dynamism, these venomous species with limited 
movement capabilities would be left behind in imperfect environmental conditions. Such is the concern for snakes; prior studies have found that phylogenetically related snake species have movement rates of 10-100 m per day, ${ }^{83-85}$ which, combined with environmental fragmentation and deforestation, may lead to many suitable climate spaces being isolated from colonization by nonindigenous snake species. ${ }^{16}$ Additionally, research has noted significant decreases in snake distribution with liberal climate projections $\left(+6.4^{\circ} \mathrm{C}\right.$ increase by 2100$)$ as opposed to conservative projection $\left(+1.1^{\circ} \mathrm{C}\right.$ increase by 2100) because the snakes would not be able to adapt quickly enough to their rapidly changing climate. ${ }^{18}$ Similar discrepancies between changing climate rates and distribution capabilities exist for spiders. For example, Loxosceles typically travel with humans to enter new geographic areas and do not have a propensity for dispersal on their own accord. ${ }^{27}$ Given this limited dispersal capability, there is a possibility of species extinction if environmental change occurs too rapidly. ${ }^{86-89}$

\section{Limitations}

The authors of this review acknowledge that many of the studies reviewed are based upon future modeling, which, although based on current-day information, is speculative in nature. Additionally, many important venomous terrestrial species were not included in this review due to the lack or absence of published studies, including black widow spiders, scorpions, and individual venomous snake species. Further research into the effects of climate change on these species would greatly help our understanding of the future of these vulnerable venomous species and their subsequent effects on human health.

The models reviewed in this study note patterns of ideal geographic ranges shifting away from the equator in poleward directions, therefore providing invasion opportunities to nonindigenous species. However, just because the new climatically ideal geographic locations may develop does not mean actual species invasion will occur because many nonclimatic factors such as migration capability must be taken into account.

\section{Conclusion}

Temperature extremes and anticipated changes to climatic norms will have a potentially dramatic effect on venomous terrestrial species. As climate change affects the distribution, populations, and life histories of many organisms, the chance of encounters could be altered, therefore affecting human encounters as well as the health and the survivability of these adaptive creatures.
Future research incorporating species movement ability would provide more clarity on the health impact climate change will have on these venomous species.

Author Contributions: Literature review (RN, IN, TE); analysis of literature (RN, IN, TE); drafting of manuscript (RN, TE); critical revision of manuscript (RN, IN, TE) approval of final manuscript (RN, IN, TE).

Financial/Material Support: None.

Disclosures: None.

\section{References}

1. Intergovernmental Panel on Climate Change, Climate Change 2014: Synthesis Report. Contribution of Working Groups I, II, Fifth Assessment Report of the Intergovernmental Panel on Climate Change. (Core Writing Team, Pachauri RK, Meyer LA, eds.) Geneva, Switzerland: IPCC; 2015.

2. White J. Bites and stings from venomous animals: a global overview. Ther Drug Monit. 2000;22(1):65-8.

3. Warrell DA. Venomous bites, stings, and poisoning. Infect Dis Clin North Am. 2012;26(2):207-23.

4. Galera C, Soohun N, Zankar N, Caimmi S, Gallen C, Demoly P. Severe anaphylaxis to bee venom immunotherapy: efficacy of pretreatment and concurrent treatment with omalizumab. J Investig Allergol Clin Immunol. 2009;19(3): 225-9.

5. Hernandez M, Gonzalez S, Galindo G, Iaz A, Rodriguez P. Reactions to Hymenoptera sting in adult patients: experience in a clinical allergy/immunology service in Monterrey Mexico. World Allergy Organ J. 2007:S216-7.

6. Campanella E. Climate change could bring venomous snakes slithering to Canada: study. Available at: https://globalnews. ca/news/2565201/climate-change-could-bring-poisonous-sna kes-slithering-to-canada-study/. Accessed March 9, 2016.

7. Pearl M. Get ready for more mosquitoes and ants thanks to climate change. https://www.vice.com/en_us/article/mg4n54/; get-ready-for-more-mosquitoes-and-ants-thanks-to-climatechange. Accessed March 30, 2017.

8. Saupe EE, Papes M, Selden PA, Vetter RS. Tracking a medically important spider: climate change, ecological niche modeling, and the brown recluse (Loxosceles reclusa). PLoS One. 2011;6(3):e17731.

9. Stock RP, Massougbodji A, Alagon A, Chippaux JP. Bringing antivenoms to sub-Saharan Africa. Nat Biotechnol. 2007;25(2):173-7.

10. O'Neil ME, Mack KA, Gilchrist J, Wozniak EJ. Snakebite injuries treated in the United States emergency departments, 2001-2004. Wilderness Environ Med. 2007;18(4): 281-7.

11. Kasturiratne A, Wickremasinghe AR, de Silva N, Gunawardena NK, Pathmeswaran A, Premaratna R, et al. The global burden of snakebite: a literature analysis and modelling based on regional estimates of envenoming and deaths. PLoS Medicine. 2008;5(11):e218.

12. Gold BS, Dart RC, Barish RA. Bites of venomous snakes. N Engl J Med. 2002;347(5):347-56. 
13. Gutierrez J, Williams D, Fan H, Warrell D. Snakebite envenoming from a global perspective: towards an integrated approach. Toxicon. 2010;56(7):1223-35.

14. Huang S, Chiou C, Lin T, Tu M, Lin C, Porter W. Future advantages in energetics, activity time, and habitats predicted in a high-altitude pit viper with climate warming. Funct Ecol. 2013;27(2):446-58.

15. Wu JG. Detecting and attributing the effects of climate change on the distributions of snake species over the past 50 years. J Environ Manage. 2016;57(1):207-19.

16. Nori J, Carrasco PA, Leynaud GC. Venomous snakes and climate change: ophidism as a dynamic problem. Clim Change. 2014;122(1-2):67-80.

17. Yanez-Arenas C, Peterson AT, Rodriguez-Medina K, Barve N. Mapping current and future potential snakebite risk in the new world. Clim Change. 2016;134(4): 697-711.

18. Lawing AM, Polly PD. Pleistocene climate, phylogeny, and climate envelope models: an integrative approach to better understand species' response to climate change. PLoS One. 2011;6(12):e28554.

19. Isbister GK, Fan HW. Spider bite. Lancet. 2011;378(9808): 2039-47.

20. Diaz JH, Leblanc KE. Common spider bites. Am Fam Physician. 2007;75(6):869-73.

21. Schneir AB, Clark RF. Bites and stings. In: Tintinalli JE, Stapczynski JS, Ma OJ, Cline DM, Cydulka RK, Meckler GD, eds. Tintinalli's Emergency Medicine. New York: McGraw Hill Medical; 2011:1347.

22. Kumschick S, Fronzek S, Entling MH, Nentwig W. Rapid spread of the wasp spider Argiope bruennichi across Europe: a consequence of climate change? Clim Change. 2011;109(3-4):319-29.

23. Rader RK, Stoecker WV, Malters JM, Marr MT, Dyer JA. Seasonality of brown recluse populations is reflected by numbers of brown recluse envenomations. Toxicon. 2012;60(1): 1-3.

24. Swanson DL, Vetter RS. Bites of brown recluse spiders and suspected necrotic arachnidism. $N$ Engl J Med. 2005;352(7):700-7.

25. Furbee RB, Kao LW, Ibrahim D. Brown recluse spider envenomation. Clin Lab Med. 2006;26(1):211-26.

26. Cramer KL, Maywright AV. Cold temperature tolerance and distribution of the brown recluse spider Loxosceles reclusa (Araneae, Sicariidae) in Illinois. J Arachnol. 2008;36(1):136-9.

27. Vetter RS. Spiders of the genus Loxosceles (Araneae, Sicariidae): a review of biological, medical, and psychological aspects regarding envenomations. J Arachnol. 2008;36(1):150-63.

28. Leroy C, Bellard C, Dubos N, Colliot A, Vasseur M, Courtial C, et al. Forecasted climate and land use changes, and protected areas: the contrasting case of spiders. Divers Distrib. 2014;20(6):686-97.

29. Bolton NS, Alpert G, Ward PS, Naskrecki P. Bolton's Catalogue of Ants of the World: 1758-2005. Cambridge, MA: Harvard University Press; 2007.
30. Suarez AV, Holway DA, Ward PS. The role of opportunity in the unintentional introduction of nonnative ants. Proc Natl Acad Sci USA. 2005;102(47):17032-5.

31. Langley R, Mack K, Haileyesus T, Proescholdbell S, Annest JL. National estimates of noncanine bite and sting injuries treated in US hospital emergency departments, 2001-2010. Wilderness Environ Med. 2014;25(1):14-23.

32. Rhoades R. Stinging ants. Curr Opin Allergy Clin Immunol. 2001;1(4):343-8.

33. Bertelsmeier C, Courchamp F. Future ant invasions in France. Environ Conserv. 2014;41(2):217-28.

34. Angiletta MJ. Thermal Adaptation: a Theoretical and Empirical Synthesis. Oxford, United Kingdom: Oxford University Press; 2009.

35. Sunday JM, Bates AE, Kearney MR, Colwell RK, Dulvy NK, Longino JT, et al. Thermal-safety margins and the necessity of thermoregulatory behavior across latitude and elevation. Proc Natl Acad Sci USA. 2014;111(15): 5610-5.

36. Roura-Pascual N, Hui C, Ikeda T, Leday G, Richardson $\mathrm{DM}$, Carpintero $\mathrm{S}$, et al. Relative roles of climatic suitability and anthropogenic influence in determining the pattern of spread in a global invader. Proc Natl Acad Sci USA. 2011;108(1):220-5.

37. Sanders NJ, Lessard JP, Fitzpatrick MC, Dunn RR. Temperature, but not productivity or geometry, predicts elevational diversity gradients in ants across spatial grains. Glob Ecol Biogeogr. 2007;16(5):640-9.

38. Dunn RR, Agosti D, Anderson AN, Arnan X, Bruhl CA, Cerdá X, et al. Climatic drivers of hemispheric asymmetry in global patterns of ant species richness. Ecol Lett. 2009; 12(4):324-33.

39. Jenkins CC, Sanders NN, Anderson AN, Arnan X, Brühl CA, Cerda X, et al. Global diversity in light of climate change: the case of ants. Divers Distrib. 2011;17(4): 652-62.

40. Bertelsmeier C, Luque GM, Hoffman BD, Courchamp F. Worldwide ant invasions under climate change. Biodivers Conserv. 2015;24(1):117-28.

41. Wetterer JK. Worldwide spread of the destroyer ant, Monomorium destructor (Hymenoptera: Formicidae). Myrmecoll News. 2009;12:97-108.

42. Bertelsmeier C, Blight O, Courchamp F. Invasions of ants (Hymenoptera: Formicidae) in light of climate change. Myrmecol News. 2016;22:25-42.

43. Otten EJ. Venomous animal injuries. In: Marx J, Hockberger R, Walls R, eds. Rosen's Emergency Medicine. 8th ed. Philadelphia, PA: Saunders Publishing; 2013.

44. Demain JG, Minaei AA, Tracy JM. Anaphylaxis and insect allergy. Curr Opin Allergy Clin Immunol. 2010;10 (4):318-22.

45. Vinson SB, Sorensen AA. Imported Fire Ants: Life History and Impact. Austin, TX: Texas Department of Agriculture; 1986.

46. Taber SW. Fire Ants. College Station TX: Texas A\&M University Press; 2000.

47. Callcott AMA. Range expansion of the imported fire ant1918-2001. Proceedings of the 2002 Annual Imported 
Fire Ant Research Conference. March 24-26, 2002; Athens, GA.

48. Callcott AMA, Collins HL. Invasion and range expansion of imported fire ants (Hymenoptera: Formicidae) in North America from 1918-1995. Fla Entomol. 1996;79 (2):240-51.

49. Mescher MC, Ross KG, Shoemaker DD, Keller L, Krieger MJB. Distribution of the two social forms of the fire ant Solenopsis invicta (Hymenoptera: Formicidae) in the native South American range. Ann Entomol Soc Am. 2003;96(6):810-7.

50. Morrill WL, Martin PB, Sheppard DC. Overwinter survival of the red imported fire ant: effects of various habitats and food supply. Environ Entomol. 1978;7(2): 262-4.

51. Francke OF, Cokendoplher JC, Potts LR. Supercooling studies on North American fire ants (Hymenoptera: Formicidae). Southwest Nat. 1986;31(1):87-94.

52. Porter SD. Impact of temperature on colony growth and developmental rate of the ant, Solenopsis invicta. J Insect Physiol. 1988;34(12):1127-33.

53. Callcott AMA, Oi DH, Collins HL, Williams DF, Lockley TC. Seasonal studies of an isolated red imported fire ant (Hymenoptera: Formicidae) population in eastern Tennessee. Environ Entomol. 2000;29(4):788-94.

54. Morrison LW, Korzukhin MD, Porter SD. Predicted range expansion of the invasive fire ant, Solenopsis invicta, in the eastern United States based on the VEMAP global warming scenario. Divers Distrib. 2005;11(3):199-204.

55. Scanlan JC, Vanderwoud C. Modelling the potential spread of Solenopsis invicta Buren (Hymenoptera: Formicidae) (red imported fire ant) in Australia. Aust J Entomol. 2006;45(1):1-9.

56. Sutherst RW, Maywald G. A climate model of the red imported fire ant, Solenopsis invicta Buren (Hymenoptera: Formicidae): implications for invasion of new regions, particularly Oceania. Environ Entomol. 2005;34(2): 317-35.

57. Kerr WE. The history of the introduction of African bees to Brazil. South African Bee J. 1967;39(2):3-5.

58. Michener CD. The Brazilian bee problem. Annu Rev Entomol. 1975;20:399-416.

59. Rinderer TE. African bees: the Africanization process and potential range in the United States. Bull Entomol Soc Am. 1986;32(4):222-7.

60. Harrison JF, Fewell JH, Anderson KE, Loper GM. Environmental physiology of the invasion of the Americas by Africanized honeybees. Integr Comp Biol. 2006;46(6): 1110-22.

61. Betten DP, Richardson WH, Tong TC, Clark RF. Massive honey bee envenomation-induced rhabdomyolysis in an adolescent. Pediatrics. 2006;117(1):231-5.

62. Bresolin NL, Carvalho LC, Goes EC, Fernandes R, Barotto AM. Acute renal failure following massive attack by Africanized bee stings. Pediatr Nephrol. 2002;17(8):625-7.

63. Franca FOS, Benvenuti LA, Fan HW, Dos Santos DR, Hain SH, Picchi-Martins FR, et al. Severe and fatal mass attacks by "killer" bees (Africanized bees-Apis mellifera scutellata) in Brazil: clinicopathological studies with measurements of serum venom concentrations. $Q \mathrm{~J}$ Med. 1994;87(5):269-82.

64. Caron DM, ed. Africanized Bees in the Americas Medina, OH: AI Root Co; 2001.

65. Schneider SS. Swarm movement patterns inferred from waggle dance activity of the Neotropical African honey bee in Costa Rica. Apidologie. 1995;26(5):395-406.

66. Taylor OR. Neotropical African (killer) bees. In: Resh V, Carde R, eds. Encyclopedia of Insects New York: Academic; 2003:776-8.

67. Winston ML. The biology and management of Africanized honey bees. Annu Rev Entomol. 1992;37(1):173-93.

68. Jarnevich CS, Esaias WE, Ma PLA, Morisette JT, Nickeson JE, Stohlgren TJ, et al. Regional distribution models with lack of proximate predictors: Africanized honeybees expanding north. Divers Distrib. 2014;20:193-201.

69. Hunter LA, Jackman JA, Sugden EA. Detection records of Africanized honey bees in Texas during 1990, 1991, and 1992. Southwest Entomol. 1993;18(2):79-89.

70. Vissher PK, Vetter RS, Baptista FC. Africanized bees, 1990-1995: initial rapid expansion has slowed in the U.S. Calif Agric. 1997;51(1):22-4.

71. US Department of Agriculture. Agricultural Research Service, March. Honeybee Research: Tucson, AZ. Spread of Africanized honey bees by year, by county. 2011. Available at: https://www. ars.usda.gov/pacific-west-area/tucson-az/honey-bee-research/ docs/africanized-honey-bees/page-5/. Accessed April, 2013.

72. Gill NS, Sangermano F. Africanized honeybee habitat suitability: a comparison between models for southern Utah and southern California. Appl Geogr. 2016;76:14-21.

73. Schneider SS, Hoffman GD, Smith DR. The African honey bee: factors contributing to a successful biological invasion. Annu Rev Entomol. 2004:49:351-76.

74. Villa JD, Koeniger N, Rinderer TE. Overwintering of Africanized, European and hybrid honey bees in Germany. Environ Entomol. 1991;20(1):39-43.

75. Villa JD, Rinderer TE, Collins AM. Overwintering of Africanized, European, and hybrid honey bees in the Andes of Venezuela. Environ Entomol. 1993;22:183-9.

76. Ruttner F, ed. Biogeography and Taxonomy of Honey Bees. Berlin, Germany: Springer-Verlag; 1988.

77. Taylor OR, Spivak M. Climatic limits of tropical African honeybees in the Americas. Bee World. 1984;65(1):38-47.

78. Parmesan C, Yohe G. A globally coherent fingerprint of climate change impacts across natural systems. Nature. 2003;421(6918):37-42.

79. Tingly MW, Koo MS, Moritz C, Rush AC, Beissinger SR. The push and pull of climate change causes heterogeneous shifts in avian elevational ranges. Global Change Biol. 2012;18(11):3279-90.

80. Root TL, Price JT, Hall KR, Schneider SH, Rosenzweig Z, Pounds JA. Fingerprints of global warming on wild animal and plants. Nature. 2003;421(6918):57-60.

81. McCarthy JP. Ecological consequences of recent climate change. Conserv Biol. 2001;15(2):320-31. 
82. Cabrelli AL, Stow AJ, Hughes L. A framework for assessing the vulnerability of species to climate change: a case study of the Australian elapid snakes. Biodivers Conserv. 2014;23(12):3019-34.

83. Macartey JM, Gregory PT, Larsen KW. A tabular survey of data movements and home range. J Herpetol. 1988;22(1): 61-73.

84. Sasa M, Wasko D, Lamar W. Natural history of the terciopelo Bothrops asper (Serpentes: Viperidae) in Costa Rica. Toxicon. 2009;54(7):904-22.

85. Hoss S, Guyer C, Smith L, Gordon W, Schuett G. Multiscale influences of landscape composition and configuration on the spatial ecology of eastern diamond-backed rattlesnakes (Crotalus adamanteus). J Herpetol. 2010;44(1):110-23.
86. Peterson AT, Soberon J, Sancez-Cordero V. Conservatism of ecological niches in evolutionary time. Science. 1999;285(285):1265-7.

87. Holt RD, Gaines MS. Analysis of adaptation in heterogeneous landscapes-implications for the evolution of fundamental niches. Evol Ecol. 1992;6(5):433-47.

88. Martinez-Meyer E, Peterson AT, Hargrove WW. Ecological niches as stable distributional constraints on mammal species, with implications for Pleistocene extinctions and climate change projections for biodiversity. Globl Ecol Biogeogr. 2004;13(4):205-314.

89. Warren DL, Glor RE, Turelli M. Environmental niche equivalency versus conservatism: quantitative approaches to niche evolution. Evolution. 2008;62(11):2868-83. 